\title{
Risco de incêndios na Estação Ecológica do Taim, Rio Grande do Sul
}

\author{
Juliana MARCHESAN ${ }^{1}$, Elisiane ALBA2*, Cristina TABARELLI ${ }^{1}$, Eliziane Pivoto MELLO ${ }^{1}$, \\ Dionatas Henrique HONNEF ${ }^{1}$, Rudiney Soares PEREIRA ${ }^{1}$
}

\author{
${ }^{1}$ Universidade Federal de Santa Maria, Santa Maria, RS, Brasil. \\ (ORCID: 0000-0002-2167-5862; 0000-0001-6857-5685; 0000-0002-8918-5720; 0000-0003-3235-3081; 0000-0002-9846-4879) \\ ${ }^{2}$ Universidade Federal Rural de Pernambuco, Unidade Acadêmica de Serra Talhada, Serra Talhada, PE, Brasil. \\ *E-mail: elisianealba@gmail.com (ORCID: 0000-0001-6210-4559)
}

Recebido em: 10/04/2019; Aceito em: 05/07/2019; Publicado em: 04/02/2020.

\begin{abstract}
RESUMO: O objetivo deste trabalho foi realizar o mapeamento das áreas suscetíveis a ocorrência de incêndios na Estação Ecológica do Taim, Rio Grande do Sul. Para a obtenção das variáveis estáticas e dinâmicas, foram utilizadas imagens do satélite Landsat 8 e imagens de Radar para a determinação da topografia da área de estudo. Como variáveis dinâmicas utilizou-se a precipitação, temperatura e uso e cobertura da terra, enquanto que variáveis estáticas foram a hipsometria, declividade e distância das estradas. Cada variável foi estratificada e posteriormente ponderada numericamente quanto a sua suscetibilidade a ocorrência a incêndio. As variáveis dinâmicas e estáticas geradas foram integradas utilizando uma equação ponderada resultando no risco de incêndios para a área de estudo. A região central da Estação Ecológica do Taim apresentou maior suscetibilidade a incêndios, englobando a classe de alto risco, totalizando 4.219,56 ha (41,61\%), enquanto as regiões periféricas apresentaram risco muito baixo a ocorrência de incêndios, abrangendo 5.419,35 ha (53,44\%). As variáveis de maior contribuição à ocorrência de incêndios corresponderam ao uso e cobertura da terra e a temperatura, sendo as áreas de maior risco localizadas na parte central e próximo às estradas, nas quais estão ocupadas por campo nativo. Assim, esses locais devem ter maior atenção e recursos para combate de possíveis incêndios.
\end{abstract}

Palavras-chave: Landsat 8; variáveis dinâmicas e estáticas; geoprocessamento.

\section{Fire risk at the Ecologial Station of Taim, Rio Grande do Sul}

\begin{abstract}
The objective of this work was to map the areas susceptible to the occurrence of fires at the Taim Ecological Station, Rio Grande do Sul. In order to obtain the static and dynamic variables, Landsat 8 satellite images and Radar images were used to determine the topography of the study area. As dynamic variables were used the precipitation, temperature and land use and coverage, while static variables were hypsometry, slope and distance of roads. Each variable was stratified and numerically weighted as to its susceptibility to fire occurrence. The dynamic and static variables generated were integrated using a weighted equation resulting in fire risk for the study area. The central region of the Taim Ecological Station presented higher susceptibility to fires, encompassing the high risk class, totaling 4,219.56 ha (41.61\%), while the peripheral regions had a very low risk of occurrence of fires, covering $5,419.35$ ha $(53.44 \%)$. The variables of greatest contribution to the occurrence of fires corresponded to the land use and land cover and the temperature, being the areas of greater risk in the central region and near the roads, in which they are occupied by the native field. Thus, these sites should have greater attention and resources to combat possible fires.
\end{abstract}

Keywords: Landsat 8; dynamic and static variables; geoprocessing.

\section{INTRODUÇÃO}

Os incêndios podem ser causados tanto por causas naturais, quanto decorrente de ações antrópicas. Primordialmente, os incêndios ocorrem devido à combinação de material combustível e condições climáticas (TETTO et al., 2012). Além disso, Torres et al. (2017) enfatizam que os incêndios são afetados pelas complexas interações entre vegetação, clima, topografia e atividades antrópicas ao longo do tempo. Saber reconhecer os locais onde existe maior probabilidade de ocorrência desses focos, possibilita a delimitação de estratégias que visem evitar o seu surgimento. A prevenção tem papel fundamental, a qual se concretiza a partir do conhecimento sobre o risco, o que permite o correto planejamento e alocação de recursos para o combate (BORGES et al., 2011).

O uso de técnicas de geoprocessamento tem auxiliado na espacialização dos fatores de riscos a incêndios, contribuindo significativamente no seu controle e prevenção (TORRES et al., 2017; PRUDENTE, 2010). Segundo Vettorazzi; Ferraz (1998), os sistemas de informações geográficas podem ser utilizados para a elaboração de mapas estratégicos de prevenção e combate, a partir de elementos como a localização de estradas, corpos de água e núcleos urbanos, possibilitando a obtenção de mapas de risco de incêndios, evidenciando regiões com maiores ou menores probabilidades de ocorrência. 
O bioma Pampa ocupa uma área que corresponde a 63\% do estado do Rio Grande do Sul, situando-se entre a zona temperada sul, apresentando um clima subtropical, com quatro estações bem definidas (ROESCH et al., 2009). Visando a conservação dos recursos naturais desse bioma, a Estação Ecológica do Taim - criada em 1986, foi classificada como unidade de conservação de proteção Integral cuja principal função é a manutenção dos ecossistemas livres de alterações causadas pela ação humana (SIMIONI; WOLLMANN, 2016).

A Estação Ecológica do Taim apresenta um histórico de incêndios naturais, o que pode comprometer a função principal da unidade. Segundo Koproski et al. (2011), poucas unidades possuem controle de incêndios e planos de prevenção com zoneamentos de risco estabelecidos. Assim, há necessidade de estudos que se destinam a elaboração de zoneamento capaz de delimitar as áreas mais suscetíveis aos incêndios na unidade de conservação do Taim, tanto para impedi-los quanto para mitigá-los por meio de manejo adequado.

O objetivo deste trabalho foi realizar o mapeamento das áreas suscetíveis a ocorrência de incêndios na Estação Ecológica do Taim, Rio Grande do Sul.

\section{MATERIAL E MÉTODOS}

Localizada na Planície Costeira do Rio Grande do Sul, a Estação Ecológica do Taim situa-se entre os municípios de Rio Grande e Santa Vitória do Palmar, nas coordenadas 6.397.586 $\mathrm{mN}$ e $6.365 .350 \mathrm{mN}$ ao sul do Equador e 344.690 $\mathrm{mE}$ e $359.027 \mathrm{mE}$ a oeste do meridiano central $\left(51^{\circ}\right)$, Fuso $22 \mathrm{~S}$, conforme a Figura 1, abrangendo aproximadamente 11 mil hectares (ICMBIO, 2018).

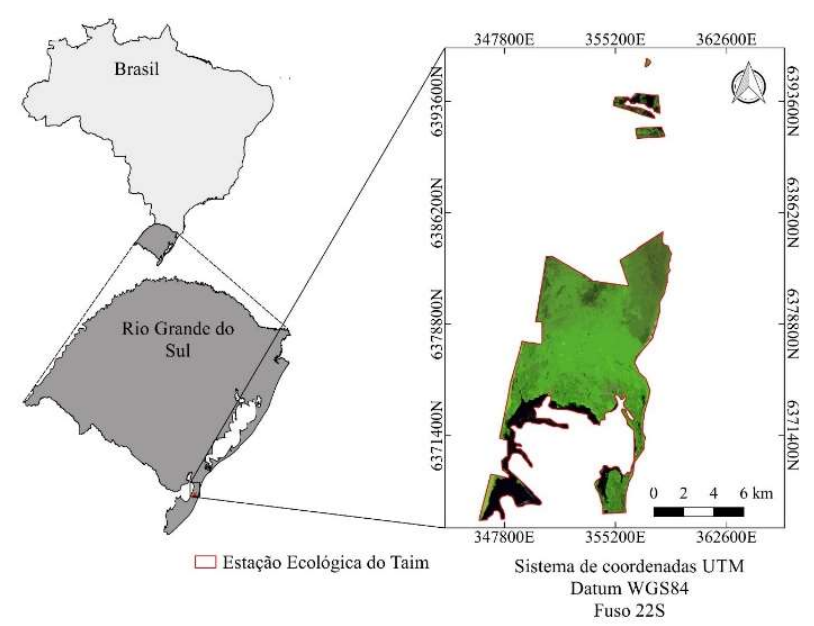

Figura 1. Localização da Estação Ecológica do Taim no estado do Rio Grande do Sul, Brasil.

Figure 1. Location of the Taim Ecological Station in Rio Grande do Sul state, Brazil.

Para a obtenção das variáveis estáticas e dinâmicas, utilizou-se imagens do satélite Landsat 8, sensor OLI (Operational Land Imager) e TIRS (Thermal Infrared Sensor), na órbita-ponto 221-83 datada em 09 de fevereiro de 2015. O Modelo Digital de Elevação (MDE) foi obtido a partir da imagem do radar SRTM (Shuttle Radar Topography Mission), banda $C$, com resolução radiométrica de 16 bits e espacial de $30 \mathrm{~m}$ (adquirida por meio de técnica de interpolação da imagem original de $90 \mathrm{~m}$ ), imageada no ano de 2000, oriunda do banco de dados da Embrapa.

Foi utilizado o software SPRING versão 5.3 para o processamento dos dados, o qual incluiu operações de recorte da imagem, bem como a elaboração dos mapa temáticos de uso e cobertura da terra, temperatura e precipitação. A ponderação dos mapas temáticos foi realizada por meio da programação LEGAL (Linguagem Espacial de Geoprocessamento Algébrico) disponível no SPRING. Para cada variável foram atribuídos pesos referente a sua influência na ocorrência de incêndios, sendo classificada em Baixa, Moderada e Alta, conforme método definido por Prudente (2010).

\subsection{Variáveis Dinâmicas}

O mapa de uso e cobertura da terra foi obtido a partir do algoritmo de classificação supervisionada Bhattacharyya, com limiar de aceitação de $99 \%$. A segmentação, processo que antecede a classificação, foi realizada de modo a dividir a imagem em regiões, sendo utilizado, dentre os métodos, o de crescimento de regiões, no qual necessitou-se definir os parâmetros de similaridade e área. Assim, foi escolhida a similaridade 30 e área 50, uma vez que, melhor se adequaram a área de estudo. As classes temáticas observadas na área estudo foram floresta, campo, agricultura, solo exposto, área alagada e água.

Ainda, foi confeccionado o mapa de temperatura da área. A temperatura é uma importante variável, uma vez que temperaturas elevadas tornam o material vegetal mais seco e suscetível a entrarem em combustão. Assim, considerando a variação térmica da área de estudo, temperaturas superiores a $26{ }^{\circ} \mathrm{C}$ receberam maior peso quanto a suscetibilidade ao fogo. Para o cálculo da temperatura utilizou-se a banda termal do sensor TIRS/Landsat 8, com resolução espacial de $100 \mathrm{~m}$ e radiométrica de 16 bits, conforme demonstrado no estudo de Alba et al. (2017).

A variável pluviométrica exerce influência sobre a ocorrência de incêndios florestais, tendo em vista as variações meteorológicas. As médias pluviométricas mensais e anuais foram obtidas utilizando dados da rede de estações pluviométricas da Agência Nacional de Águas (ANA). Seis estações meteorológicas localizadas próximas a área de estudo foram utilizadas, sendo elas: Granja São Pedro, Arroio Grande, Granja Coronel Pedro Osório, Granja Cerrito, Granja Santa Maria e Granja Osório. Nas mesmas foram coletados dados de precipitação diárias dos meses de janeiro e fevereiro dos anos de 1982 a 2015, excluindo-se os anos de 1996, 2009, 2010 e 2014 devido os dados serem inconsistente, totalizando assim 30 anos. Realizou-se a média dos valores mensais e anuais dos 30 anos de coleta, obtendose assim um valor único para cada estação meteorológica. Os polígonos de Thiessen foram utilizados para determinar a área de influência das estações o que possibilitou calcular a precipitação média na área de estudo.

Foram atribuídos pesos as variáveis de acordo com o indicado por Prudente (2010). A Tabela 1 demonstra a ponderação para as variáveis dinâmicas.

\subsection{Variáveis Estáticas}

Prudente (2010) define que as baixas elevações tendem a apresentar estações de riscos de incêndios mais longas que em áreas mais elevadas. Isso se deve ao fato de que com o aumento da altitude, observa-se um decréscimo da 
temperatura e, consequentemente, um valor elevado de umidade relativa (CHUVIECO; CONGALTON, 1989). Dessa forma, as classes hipsométricas que foram utilizadas e seus respectivos pesos quanto aos níveis de suscetibilidade ao fogo estão demonstradas na Tabela 2.

Tabela 1. Variáveis dinâmicas para a avaliação da suscetibilidade à incêndios.

Table 1. Dynamic variables for the assessment of fire susceptibility.

\begin{tabular}{llc}
\hline Cobertura da terra & $\begin{array}{l}\text { Combustibilidade da } \\
\text { vegetação }\end{array}$ & Peso \\
\hline Água, área alagada & Baixa & 1 \\
Floresta, solo exposto & Baixa & 1 \\
Agricultura & Moderada & 2 \\
Campo & Alta & 3 \\
\hline Temperatura $\left({ }^{\circ} \mathrm{C}\right)$ & Suscetibilidade ao fogo & Peso \\
\hline$<24$ & Baixo & 1 \\
$24-26$ & Moderado & 2 \\
$>26$ & Alto & 3 \\
\hline Precipitação $(\mathrm{mm})$ & Suscetibilidade ao fogo & Peso \\
\hline 113 & Moderada & 2 \\
114 & Moderada & 2 \\
\hline
\end{tabular}

Tabela 2. Variáveis estáticas para a avaliação da suscetibilidade à incêndios.

Table 2. Static variables for fire susceptibility assessment.

\begin{tabular}{llc}
\hline Elevação $(\mathrm{m})$ & Suscetibilidade ao fogo & Peso \\
\hline$<5$ & Alta & 3 \\
$5-10$ & Moderada & 3 \\
$>15$ & Baixa & 1 \\
\hline Declividade $(\%)$ & Suscetibilidade ao fogo & Peso \\
\hline$<3$ & Baixa & 1 \\
$3-5$ & Baixa & 1 \\
$5-10$ & Moderada & 2 \\
$>10$ & Alta & 3 \\
\hline Distância & Suscetibilidade ao fogo & Peso \\
\hline Até 50 & Influente & 3 \\
$>50$ & Não influente & 0 \\
\hline
\end{tabular}

O mapa de declividade foi desenvolvido a partir do MDE da área de estudo, definindo quatro classes de declividade para a atribuição de pesos, adaptando o método de Ribeiro et al. (2008). Segundo Ferraz; Vettorazzi (1998), as áreas próximas às rodovias estão relacionadas a alto risco de incêndios, devido ao fluxo intenso de pessoas nesses locais. Assim, o mapa de proximidade das estradas foi obtido por meio da malha viária do estado do Rio Grande do Sul, elaborando uma zona de amortecimento fixada de $50 \mathrm{~m}$ de distância das estradas. Desse modo, até $50 \mathrm{~m}$ da estrada, considerou-se influente recebendo peso 3 e acima da zona de amortecimento, não sendo influente, recebendo o valor 0 .

\subsection{Mapeamento da suscetibilidade ao fogo}

Os mapas das variáveis dinâmicas e estáticas gerados foram integrados utilizando uma equação matemática ponderada (Equação 1). Assim, obteve-se o mapa de risco final, gerando uma representação espacial com as classes de suscetibilidade à incêndios: muito baixo, baixo, moderado, alto e muito alto. em que: $\mathrm{R}=$ risco de incêndio; $\mathrm{USO}=$ uso da terra e cobertura vegetal; $\mathrm{DEC}=$ declividade; $\mathrm{DE}=$ distância de estradas; $\mathrm{P}=$ precipitação; $\mathrm{T}=$ temperatura média do ar; $\mathrm{HIP}=$ hipsometria.

Com base nas variáveis de estudo e sua importância quanto a suscetibilidade à combustão, foram atribuídos diferentes pesos, sendo essa equação uma adaptação do método de Prudente (2010). A variável uso da terra recebeu o maior peso (30), uma vez que o fogo não ocorre, nem se propaga sem a existência de material combustível. Desse modo, esta variável tem maior importância no modelo quando comparadas às demais variáveis.

\section{RESULTADOS}

A Figura 2 demonstra as varáveis dinâmicas e suas respectivas classes. As precipitações médias, analisadas em um período de 30 anos, variaram de 113,26 a $114,05 \mathrm{~mm}$. Na área houve predominância de temperatura mediana $(24-26$ ${ }^{\circ} \mathrm{C}$ ), enquanto que o mapeamento do uso e cobertura da terra evidenciou as características da região, a qual apresenta predomínio dos banhados e áreas de campo.

$\mathrm{Na}$ Figura 3 estão expostas as variáveis estáticas, composta pela hipsometria, declividade e distância das estradas. Observou-se que a área da Estação Ecológica é composta principalmente por uma classe de elevação e declividade, indicando um relevo plano. A área de estudo apresenta-se distante das estradas, apenas uma pequena porção da Estação Ecológica possui influência dos efeitos adversos provenientes de sua proximidade com a rede viária (Figura 3C).

O cruzamento das variáveis dinâmicas e estáticas foi realizado por meio da programação LEGAL, disponível no SPRING, a qual possibilita realizar operações matemáticas e combinar mapas, assim, a partir da Equação 1 foi possível obter o mapa numérico de suscetibilidade à ocorrência de incêndios, resultando em valores de 80 a 205, segundo os quais foi definida a amplitude total e assim, dividido em cinco classes de intervalo igual (Tabela 3). Essas cinco classes descrevem o grau de suscetibilidade à incêndio na Estação Ecológica.

Tabela 3. Definição das classes de suscetibilidade a ocorrência de incêndios.

Table 3. Definition of the susceptibility classes the occurrence of fires.

\begin{tabular}{ccc}
\hline Fatiamento & Classe \\
\hline $80-\mid$ & 105 & Muito baixo \\
$105-\mid$ & 120 & Baixo \\
$130-\mid$ & 155 & Moderado \\
$155-\mid$ & 180 & Alto \\
$180-\mid$ & 205 & Muito alto \\
\hline
\end{tabular}

A Figura 4 ilustra o mapa de risco de incêndios, demonstrando que a parte central - tons de laranja apresenta propensão a ocorrência de incêndios. A Tabela 4 demonstra a quantificação do mapa de suscetibilidade a ocorrência de incêndios. A maior parte da área associou-se à classe de muito baixo risco, a qual englobou 5.419,35 ha, correspondendo a $53,44 \%$ da área total.

$\mathrm{Na}$ sequência, outra parte da Estação Ecológica foi abrangida pela classe de alto risco a incêndios, ocupando $4.219,56$ ha, equivalente a 41,61\% da área. As demais classes ocuparam percentual de área de menor expressividade. 


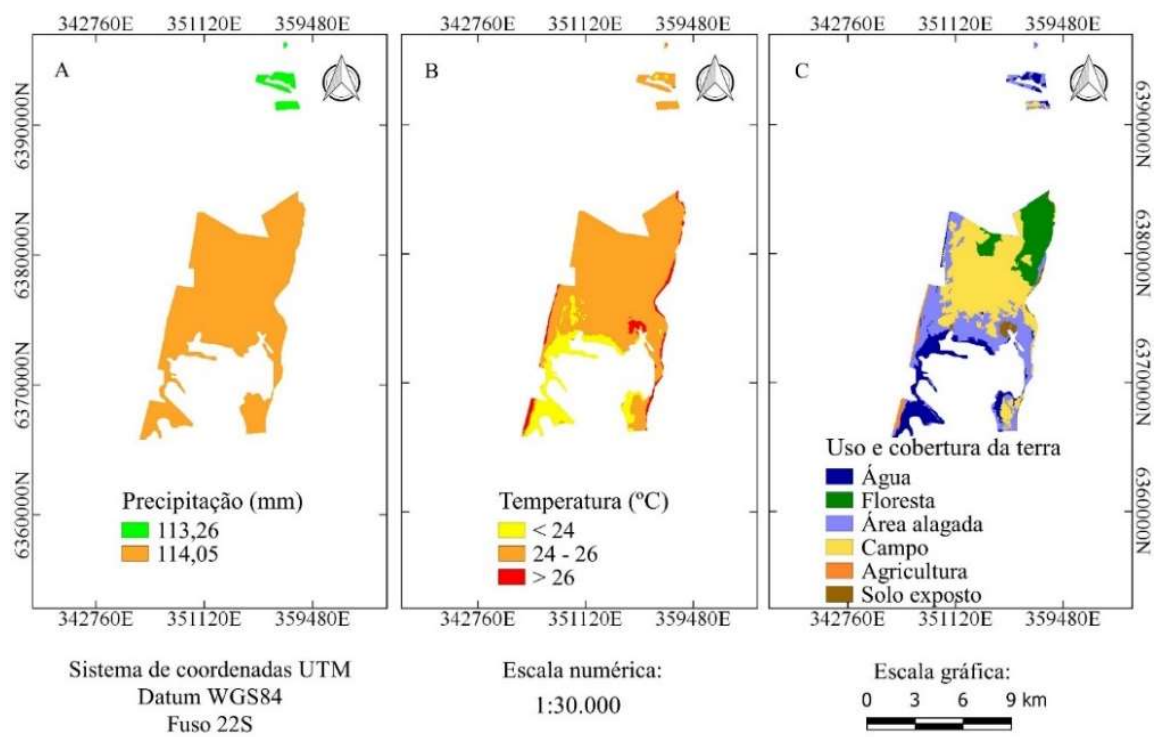

Figura 2. Mapeamento da precipitação (A), temperatura (B) e uso e cobertura da terra (C).

Figure 2. Mapping of precipitation (A), temperature (B) and land use and land cover (C).

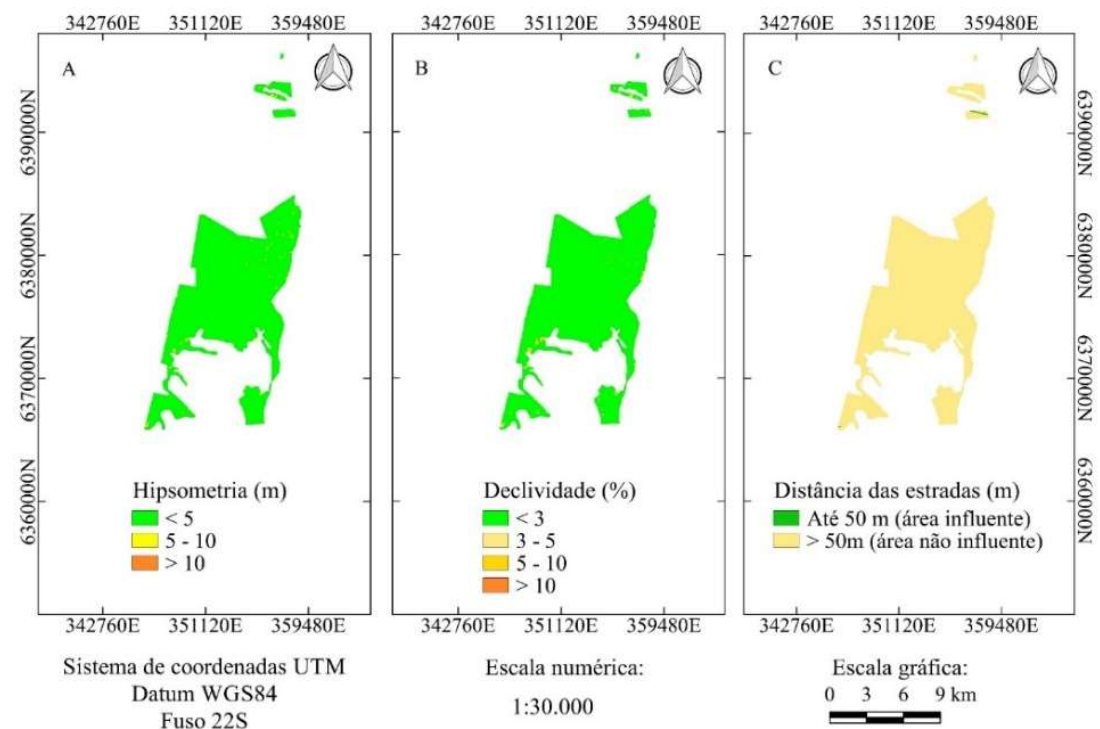

Figura 3. Mapeamento da hipsometria (A), declividade (B) e distância das estradas (C). Figure 3. Mapping of hypsometry (A), slope (B) and distance of roads (C).

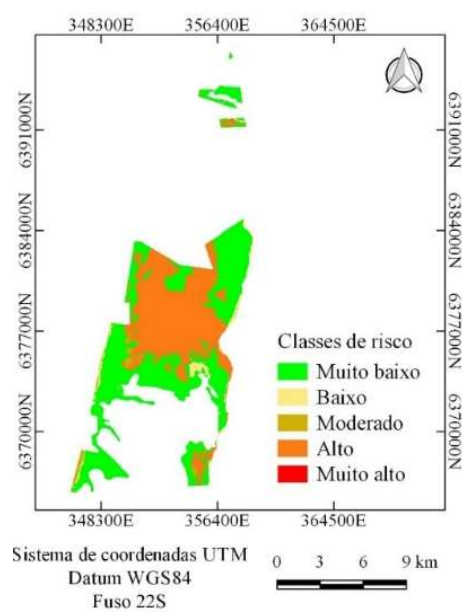

Figura 4. Mapa de suscetibilidade de risco de incêndio. Figure 4. Map of susceptibility to fire hazard.
Tabela 4. Quantificação da suscetibilidade de risco de incêndio. Table 4. Quantification of susceptibility of fire risk.

\begin{tabular}{crr}
\hline \multirow{2}{*}{ Classe de risco } & \multicolumn{2}{c}{ Área } \\
\cline { 2 - 3 } & ha & $\%$ \\
\hline Muito baixo & $5.419,35$ & 53,44 \\
Baixo & 312,21 & 3,08 \\
Moderado & 188,19 & 1,86 \\
Alto & $4.219,56$ & 41,61 \\
Muito alto & 1,35 & 0,013 \\
\hline Total & $10.140,66$ & 100,00 \\
\hline
\end{tabular}

\section{DISCUSSÃO}

De modo geral, as classes com maior abrangência foram a de alto e muito baixo risco de incêndio. Esses resultados demonstram que as áreas ocupadas com campo nativo, juntamente com a proximidade das estradas, foram os 
principais fatores que elevaram o risco de ocorrência de incêndios na área de estudo.

As classes de menor suscetibilidade a ocorrência de incêndios incluem áreas com cobertura florestal e área alagadas. As áreas com alto risco de incêndios concentram-se em solos cobertos por vegetação rasteira (Campo nativo) e com temperaturas de 24 a $26^{\circ} \mathrm{C}$, condições essas, propícias para incidência de fogo. $\mathrm{O}$ mesmo comportamento foi observado por Ferraz; Vettorazzi (1998).

O campo, especialmente em períodos de estiagem, tornase altamente inflamável, uma vez que há um aumento da concentração de material combustível, caracterizado pela palha seca disposta sobre a superfície. Desse modo, a produção de material combustível fornece condições favoráveis para incêndios, pois contempla um dos lados do triângulo do fogo, que combinados com uma fonte de ignição, seja natural (raio) ou antrópica, pode acarretar um incêndio de grandes proporções, sendo assim, essencial a identificação desses pontos mais suscetíveis a esse fenômeno.

Nesse sentido, o bioma Pampa é caracterizado pela cobertura campestre com a presença de maciços florestais isolados. Diante dessa condição de uso da terra, incêndios quando não controlados, pode comprometer a biodiversidade local.

Destaca-se que as áreas próximas à estrada, englobaram maiores risco de incêndios. Esse mesmo comportamento foi observado por Torres et al. (2017), os quais observaram uma diminuição das ocorrências de incêndios à medida que se afasta dos eixos das estradas e das áreas urbanas, ocorrendo a partir de determinada distância, um novo aumento.

Segundo Mathe (2013), áreas mais propensas a incêndios e dano potencial consideravelmente elevados, estão associados em áreas com atividade humana intensa. A população interfere nos ciclos anuais do fogo, diminuindo ou aumentando as épocas e áreas mais propícias à ocorrência de incêndios (TORRES et al., 2017). Para Bedia et al. (2015), a intervenção humana afeta o início do evento, exercendo um controle importante da atividade do fogo além de suas limitações naturais, mascarando a influência do clima.

Outro fator relevante na identificação de incêndios é a precipitação. Para Tetto et al. (2012), as ocorrências de incêndios florestais no estado do Paraná estão diretamente relacionadas à quantidade e distribuição da precipitação pluviométrica. Os autores observaram que existe uma maior correlação entre o número de ocorrências de incêndio e a precipitação $(r=-0,77)$ do que entre a área afetada e a precipitação $(r=-0,14)$.

No mesmo âmbito, Torres et al. (2016) destacaram que a precipitação é o fator de maior influência para a ocorrência de incêndios, sendo os períodos de estiagem os que necessitam de maior atenção. Aliado a estes fatores, encontram-se as altas temperaturas e as baixas umidades relativa do ar (SANTOS et al., 2017). No presente estudo, a precipitação foi constante e pouco influente no risco de incêndios, uma vez que foi abordada em uma escala local, contendo poucas variações.

\section{CONCLUSÕES}

As variáveis de maior contribuição à ocorrência de incêndios correspondem ao uso e cobertura da terra e a temperatura em decorrência das características da região de estudo. O mapa de suscetibilidade demonstra que as áreas de maior risco a ocorrência de incêndios estão localizadas na parte central da Estação Ecológica e próximo às estradas, nas quais estão ocupadas por campo nativo, sendo esse, o uso de maior risco a ocorrência de focos de incêndios. Esses locais devem ter maior atenção e recursos para combate de possíveis incêndios, diminuindo assim perdas na biodiversidade ali existentes e protegidas.

O mapa poderá servir de base para o manejo da área com o intuito de prevenir contra a ocorrência de novos focos de incêndio, especialmente nos locais onde predomina o campo nativo.

\section{REFERÊNCIAS}

ALBA, E.; MARCHESAN, J.; SILVA, E. A.; MELLO, E. P.; PEDRALI, L.; PEREIRA, R. S. Identificação de ilhas de calor e sua relação com a fisionomia da paisagem. In: SIONE, W.F.; MAYER, F. M. V.; ANTES, M. E.; SERAFINI, M. C. (Ed). Geotecnologías, herramientas para la construcción de una nueva visión del cambio global y su transformación para un futuro sostenible: Libro de Actas de XVII Simposio Internacional en Percepción Remota y Sistemas de Información Geográfica. Luján: EdUnLu, 2017. p. 429 - 438.

BEDIA, J.; HERRERA, S.; GUTIÉRREZ, J. M.; BENALI, A.; BRANDS, S.; MOTA, B.; MORENO, J. M. Global patterns in the sensitivity of burned area to fire-weather: implications for climate change. Agricultural and Forest Meteorology, Amsterdam, v. 214-215, p. $369-$ 379, 2015.2 DOI: https://doi.org/10.1016/j.agrformet.2015.09.002

BORGES, T. S.; FIEDLER, N. C.; SANTOS, A. R.; LOUREIRO, E. B.; MAFIA, R. G. Desempenho de alguns índices de risco de incêndios em plantios de eucalipto no norte do Espírito Santo. Floresta e Ambiente, Seropédica, v. 18, n. 2, p. 153 - 159, 2011. DOI: http://dx.doi.org/10.4322/floram.2011.033

CHUVIECO, E.; CONGALTON, R. G. Application of remote sensing and geographic information systems to forest fire hazard mapping. Remote Sensing Enviromment, Amsterdam, v. 29, n. 2, p. 147 - 159, 1989. DOI: https://dx.doi.org/10.1016/00344257(89)90023-0

FERRAZ, S. F. B.; VETTORAZZI, C. A. Mapeamento de risco de incêndios florestais por meio de sistema e informações geográficas (SIG). Scientia Forestalis, Piracicaba, n. 53, p. 39 - 48, jun. 1998.

INSTITUTO CHICO MENDES DE CONSERVAÇÃO DA BIODIVERSIDADE (ICMBIO). Esec do Taim. $2018 . \quad$ Disponível em: http://www.icmbio.gov.br/portal/unidadesdeconservac ao/biomasbrasileiros/marinho/unidades-deconservacao-marinho/2257-esec-do-taim. Acesso em: 29 jan. 2018.

KOPROSKI, L.; FERREIRA, M. P.; GOLDAMMER, J. G.; BATISTA, A. C. Modelo de zoneamento de risco de incêndios para unidades de conservação brasileiras: o caso do Parque Estadual do Cerrado (PR). Floresta, Curitiba, v. 41, n. 3, p. 551 - 562, 2011. DOI: http://dx.doi.org/10.5380/rf.v41i3.24049

MATHE, M. F. Modelação SIG na avaliação do risco de incêndio na Reserva Nacional do Niassa. 2013. 114f. Dissertação (Mestrado em Ciências e Sistemas de 
Informação Geográfica) - Universidade Nova de Lisboa, Lisboa, 2013.

PRUDENTE, T. D. Geotecnologias aplicadas ao mapeamento de risco de incêndio florestal no parque nacional da Chapada dos Veadeiros e áreas de entorno. 2010. 114f. Dissertação (Mestrado em Geografia) - Universidade Federal de Uberlândia, Uberlândia, 2010.

RIBEIRO, L.; KOPROSKI, L. P.; STOLLE, L.; LINGNAU, C.; SOARES, R. V.; BATISTA, A. C. Zoneamento de riscos de incêndios florestais para a Fazenda Experimental do Canguiri, Pinhais (PR). Revista Floresta, Curitiba, v. 38, n. 3, p 561 - 572, 2008. DOI: http://dx.doi.org/10.5380/rf.v38i3.12430

ROESCH, L. F. W.; VIEIRA, F. C. B.; PEREIRA, V. A.; SCHUNEMANN, A. L.; TEIXEIRA, I. F.; SENNA, A. J. T.; STEFENON, V. M. The brazilian Pampa: a fragile biome. Diversity, Basel, v. 1, p. 182 - 198, 2009. DOI: DOI: https://dx.doi.org/10.3390/d1020182

SANTOS, W. S.; SOUTO, P. C.; SOUTO, J. S. Estimativa de risco de incêndios florestais em unidades de conservação no bioma caatinga no estado da Paraíba, Brasil. Nativa, Sinop, v. 5, n. 6, p. 440 - 445, 2017. DOI: http://dx.doi.org/10.5935/2318-7670.v05n06a10

SIMIONI, J. P. D.; WOLLMANN, C. A. Caracterização e variabilidade interanual da precipitação pluviométrica na Estação Ecológica do Taim, Rio Grande do Sul, no período de 1996 a 2009. Revista Brasileira de Climatologia, Curitiba, v. 18, p. 194 - 206, 2016. DOI: http://dx.doi.org/10.5380/abclima.v18i0.34967

TETTO, A. F.; BATISTA, A. C.; SOARES, R. V. Ocorrência de incêndios florestais no estado do Paraná, no período de 2005 a 2010. Floresta, Curitiba, v. 42, n. 2, p. $391-$ 398, 2012.2 DOI: http://dx.doi.org/10.5380/rf.v42i2.22516

TORRES, F. T. P.; LIMA, G. S.; COSTA, A. L. G.; FÉLIX, G. A.; SILVA JÚNIOR, M. R. Perfil dos incêndios florestais em unidades de conservação brasileiras no período de 2008 a 2012. Floresta, Curitiba, v. 46, n. 4, p. 531 - 542, out./dez. 2016. DOI: http://dx.doi.org/10.5380/rf.v46i4.44199

TORRES, F. T. P.; ROQUE, M. P. B.; LIMA, G. S.; MARTINS, S. V.; FARIA, A. L. L. Mapeamento do risco de incêndios florestais utilizando técnicas de geoprocessamento. Floresta e Ambiente, Seropédica, v. 24, p. 1 - 10, 2017. DOI: http:/ /dx.doi.org/10.1590/2179-8087.025615

VETTORAZZI, C. A.; FERRAZ, S. F. Uso de sistemas de informações geográficas aplicados à prevenção e combate a incêndios em fragmentos florestais. Série Técnica IPEF, Piracicaba: 1997, v. 12, n. 32, p. 111 - 115, dez. 1998. 